\title{
Numerical simulation of transverse thermal expansion of FRP bars embedded in concrete slabs
}

\author{
[Samia Lardjane ${ }^{1}$, Hizia Bellakehal ${ }^{1}$, Ali Zaidi ${ }^{1}$, Radhouane Masmoudi $^{2}$ ]
}

\begin{abstract}
The thermal behavior is one of the main drawbacks of fiber reinforced polymer (FRP) bars embedded in concrete due to the significant difference between the transverse coefficient of thermal expansion of FRP bars and that of concrete. This difference generates a radial pressure at the FRP bar/concrete interface under high temperatures, and may cause splitting cracks within concrete. This paper presents a numerical study using ADINA finite elements software to predict transverse thermal strains in glass FRP (GFRP) bars and concrete cover of GFRP bars-reinforced concrete slabs submitted to a temperature increase varied from -50 to $+60^{\circ} \mathrm{C}$ and having a ratio of concrete cover thickness to FRP bar diameter varied from 1.3 to 2.8 . The transverse thermal strains, at FRP bar/concrete interface and at external surface of concrete cover, obtained from the numerical model are compared with those obtained from the analytical model and experimental tests.
\end{abstract}

Keywords - Numerical simulation, Concrete cover, FRP bars, Slab, Temperature, Transverse strains, Cracking temperatures.

\section{Introduction}

To minimize corrosion of steel in reinforced concrete structures and build more durable constructions, various corrosion protection strategies have been adopted such as galvanic steel protection, epoxy coated reinforcement and cathodic protection. But none has been totally successful in eliminating corrosion (ACI 440.1R.06.2006). These findings have resulted in a completely different approach, which is to use materials of highly corrosion resistant, such as reinforcing bars fabricated from fiber reinforced polymers (FRP) characterized by their non-corrosive structure, high tensile strength and light weight. However, the main drawback of FRP bars is the lack of thermal compatibility between concrete and FRP reinforcement. The coefficient of thermal expansion (CTE) of glass FRP (GFRP) bars in the transverse direction is 3 times greater than that in the longitudinal direction. Also, is greater than the CTE of hardened concrete (Masmoudi et al. 2005, Chaallal et al. 1993).

Samia Lardjan Hizia Bellakehal, and Ali Zaidi

Structures Rehabilitation and Materials Laboratory (SREML), University of Laghouat,

Algeria

Radhouane Masmoudi

Department of Civil Engineering, University of Sherbrooke, QC. Canada
This transverse thermal incompatibility between concrete and GFRP bars induces radial tensile stresses in concrete under low temperature and circumferential tensile stresses under high temperature, and may cause respectively, circumferential and radial cracks within concrete. These thermal cracks may cause the degradation of the bond between FRP bar and concrete if the confining pressure of concrete is insufficient. Consequently, durability and serviceability of reinforced concrete structures could be affected. This paper presents a numerical study using ADINA finite elements software to predict transverse thermal strains in FRP bars and concrete cover of reinforced concrete slabs submitted to a temperature variation varied from -50 to $+60^{\circ} \mathrm{C}$ and having a ratio of concrete cover thickness to FRP bar diameter $\left(\mathrm{c} / \mathrm{d}_{\mathrm{b}}\right)$ varied from 1.3 to 2.8 . The results of transverse thermal strains in FRP bars reinforced concrete slabs predicted from the nonlinear finite element model are compared with those obtained from the analytical model and experimental tests.

\section{Finite Element Investigation}

\section{A. Finite Element Model}

In order to analyze the distribution of transverse thermal strains in the concrete cover surrounding GFRP bars, a nonlinear numerical simulation was carried out utilizing ADINA finite elements (FE) software for GFRP bars reinforced concrete slabs under temperature variation varied from -50 to $+60^{\circ} \mathrm{C}$. The slabs were $500 \mathrm{~mm}$ wide, 195 to 215 $\mathrm{mm}$ thick, $2500 \mathrm{~mm}$ total length, and $2000 \mathrm{~mm}$ span between supports. The slabs were submitted to temperature variation from 0 to $-50^{\circ} \mathrm{C}$ with an increment of $-5^{\circ} \mathrm{C}$, and then from 0 to $60^{\circ} \mathrm{C}$ with an increment of $+5^{\circ} \mathrm{C}$. The ratio of concrete cover thickness to FRP bars diameter $\left(\mathrm{c} / \mathrm{d}_{\mathrm{b}}\right)$ used is varied from 1.3 to 2.8, as shown in Table 1. All experimental tests have been numerically reproduced using the FE-code ADINA. Since the slabs are symmetric with respect to $\mathrm{z}-\mathrm{x}$ and $\mathrm{z}-\mathrm{y}$ planes, the study was carried out only for the quarter of slabs. 3D-solid with 8-nodes was used for the meshing of concrete and GFRP bars, as shown in Fig.1.

The mechanical properties of concrete and GFRP bars are those determined experimentally by Bellakehal et al. (2013 and 2014). The mechanical properties of concrete are presented in Table 2. The elasticity modulus of concrete was calculated as recommended by the code ASTM C 46902. Poisson's ratio and coefficient of thermal expansion of concrete are assumed equal to 0.17 and $11.7 \times 10^{-} 6 /{ }^{\circ} \mathrm{C}$, respectively. The mechanical properties of GFRP bars used in this study are presented in Table 3 . The transverse modulus of elasticity $\left(E_{t}\right)$ and Poisson's ratio of GFRP bars in the transverse direction $\left(v_{\mathrm{tt}}\right)$ were evaluated theoretically. 
Proc. of the Sixth Intl. Conf. Advances in Civil, Structural and Mechanical Engineering - CSM 2018

Copyright ( $)$ Institute of Research Engineers and Doctors, USA. All rights reserved.

ISBN: 978-1-63248-150-4 doi: 10.15224/978-1-63248-150-4-24

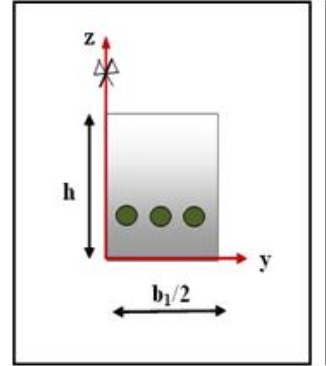

(a)

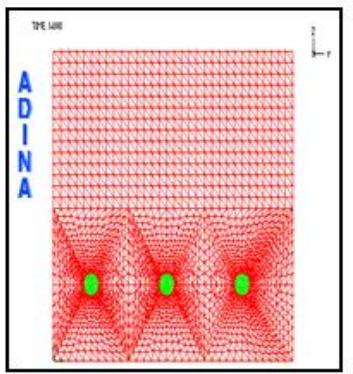

(b)

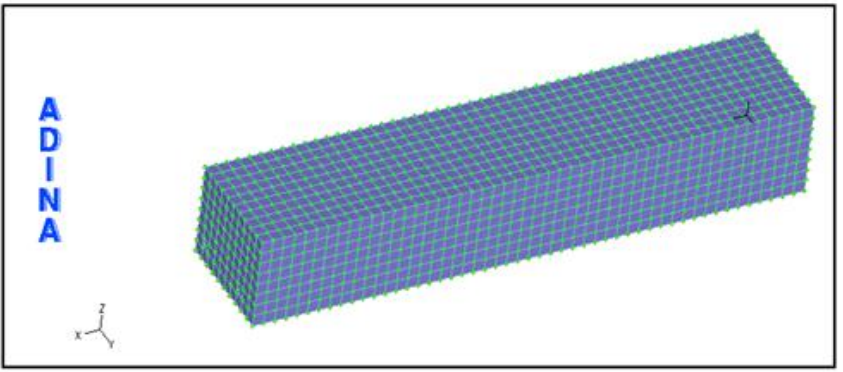

(c)

Figure 1. Modeling of typical concrete slab reinforced with six GFRP bars: (a) half of slab cross-section, (b) meshing of the half of slab cross-section, (c) meshing of the quarter of concrete slab.

Table 1. Detail of concrete slabs reinforced with GFRP bars

\begin{tabular}{|c|c|c|c|c|c|c|c|c|}
\hline Slabs & $\begin{array}{l}\text { Height } \\
\mathrm{h}(\mathrm{mm})\end{array}$ & $\begin{array}{c}\text { Width } \\
\mathrm{b}_{1}(\mathrm{~mm})\end{array}$ & $\begin{array}{l}\text { concrete cover } \\
\text { c }(\mathrm{mm})\end{array}$ & $\begin{array}{c}\text { Bar diameter } \\
\mathrm{d}_{\mathrm{b}}(\mathrm{mm})\end{array}$ & Bars number & $\begin{array}{c}\text { Spacing between bars }{ }^{\mathrm{b}} \\
\mathrm{e}(\mathrm{mm})\end{array}$ & $\mathrm{c} / \mathrm{d}_{\mathrm{b}}$ & $\mathrm{e} / \mathrm{d}_{\mathrm{b}}$ \\
\hline S.195.16.25 & 195 & 500 & 25 & 15.9 & 06 & 70.92 & 1.57 & 4.46 \\
\hline S.195.19.25 & 195 & 500 & 25 & 19.1 & 04 & 124.53 & 1.31 & 6.52 \\
\hline S.200.16.30 & 200 & 500 & 30 & 15.9 & 06 & 68.92 & 1.89 & 4.33 \\
\hline S.200.19.30 & 200 & 500 & 30 & 19.1 & 04 & 121.20 & 1.57 & 6.35 \\
\hline S.215.16.45 & 215 & 500 & 45 & 15.9 & 06 & 62.92 & 2.83 & 3.96 \\
\hline S.215.19.45 & 215 & 500 & 45 & 19.1 & 04 & 111.20 & 2.36 & 5.82 \\
\hline
\end{tabular}

a S. 195.16.25: Refers to slab having a thickness of $195 \mathrm{~mm}$, reinforced with GFRP bars $\mathrm{N}^{\circ} 16$, and having a concrete cover thickness of $25 \mathrm{~mm}$.

${ }^{\mathrm{b}}$ Spacing is measured between FRP bars centers.

The longitudinal modulus of elasticity is determined as recommended by the code ACI 440.3R-04. The coefficients of thermal expansion were measured by the Thermo Mechanical Analysis (TMA) test as recommended by the Standard ASTM E831. The other properties are the manufacturer's specified values.

\section{B. Numerical Results and Discussions}

Fig. 2 shows transverse thermal strains versus temperature variations $(\Delta T)$ at FRP bar/concrete interface of concrete slabs reinforced with GFRP bars having a ratio of concrete cover thickness to FRP diameter $\left(c / d_{b}\right)$ varied from 1.3 to 2.8 . It can be observed that the transverse thermal strains are varied linearly for $\Delta T$ varied from $-50^{\circ} \mathrm{C}$ to $+60^{\circ} \mathrm{C}$. This figure shows that the variation of concrete cover thickness has no big effect on the transverse thermal strains at FRP bar/concrete interface for reinforced concrete slabs. However, the transverse thermal strains of slabs reinforced with GFRP bars $\mathrm{N}^{\circ} 16$ are greater than those of slabs reinforced with GFRP bars $\mathrm{N}^{\circ} 19$. This is due to the lower value of the transverse coefficient of thermal expansion of GFRP bars $\mathrm{N}^{\circ} 19$ compared to that of GFRP bars $\mathrm{N}^{\circ} 16$ (Table 3).

Table 2. Mechanical properties of concrete.

\begin{tabular}{llll}
\hline Slabs & $\begin{array}{l}\text { Longitudinal } \\
\text { modulus of } \\
\text { elasticity } \\
\mathrm{E}_{\mathrm{c}}(\mathrm{GPa})\end{array}$ & $\begin{array}{l}\text { Compressive } \\
\text { strength } \\
(\mathrm{MPa})\end{array}$ & $\begin{array}{l}\text { Tensile strength } \\
f_{c t}(\mathrm{MPa})\end{array}$ \\
\hline $\mathrm{S} .195 .16 .25$ & $26.17 \pm 0.4$ & $33.83 \pm 1$ & $1.94 \pm 0.04$ \\
\hline $\mathrm{S} 195.19 .25$ & $26.53 \pm 0.3$ & $34.77 \pm 0.7$ & $2.77 \pm 0.15$ \\
\hline $\mathrm{S} .200 .16 .30$ & $24.80 \pm 0.8$ & $30.39 \pm 2$ & $2.58 \pm 0.04$ \\
\hline S200.19.30 & $27.34 \pm 0.7$ & $36.93 \pm 2$ & $2.92 \pm 0.25$ \\
\hline $\mathrm{S} 215.16 .45$ & $26.17 \pm 0.4$ & $33.83 \pm 1$ & $1.94 \pm 0.04$ \\
\hline S215.19.45 & $27.34 \pm 0.7$ & $36.93 \pm 2$ & $2.92 \pm 0.25$ \\
\hline
\end{tabular}

Fig. 3 presents the transverse thermal strains curves at the external surface of concrete cover of GFRP-bar reinforced concrete slabs having different ratio of concrete cover thickness to FRP bar diameter $\left(\mathrm{c} / \mathrm{d}_{\mathrm{b}}\right)$ varied from 1.3 to 2.8 . It can be observed that the transverse thermal strains are linear and similar up to temperature variation producing the total failure of concrete cover, from which the curves become nonlinear due to the splitting cracks which reach the external surface of concrete cover. It can be concluded that the variation of concrete cover thickness does not have a big influence on transverse thermal strains at the external surface of concrete cover. However, temperature values producing the total failure of concrete cover are greatly affected.

\section{Analytical Background}

The analytical model used in this study is based on the elasticity theory. Masmoudi et al. (2005), Aiello et al. (2001) and Rahman et al. (1995) have developed analytical models for concrete cylinder reinforced with FRP bar submitted to temperature variation $(\Delta \mathrm{T})$.

Table 3. Mechanical properties of GFRP bars

\begin{tabular}{lll}
\hline Property Designation & \multicolumn{2}{c}{$\begin{array}{c}\text { Property Value of } \\
\text { GFRP bars }\end{array}$} \\
\hline Bars diameter $\mathrm{d}_{\mathrm{b}}(\mathrm{mm})$ & 15.9 & 19.1 \\
\hline Longitudinal Modulus of elasticity, $\mathrm{E}_{\mathrm{fl}}(\mathrm{GPa})$ & $47 \pm 0.3$ & $52.2 \pm 1.2$ \\
\hline Transverse Modulus of elasticity, $\mathrm{E}_{\mathrm{ft}}(\mathrm{GPa})$ & 7.75 & 7.87 \\
\hline Poisson's ratio in the longitudinal direction, $\mathrm{v}_{\mathrm{lt}}$ & $0.28 \pm 0.005$ & $0.28 \pm 0.008$ \\
\hline Poisson's ratio in the transverse direction, $\mathrm{v}_{\mathrm{tt}}$ & 0.38 & 0.38 \\
\hline Ultimate tensile Strength $(\mathrm{MPa})$ & $700 \pm 24$ & $691 \pm 7$ \\
\hline Guarantee tensile Strength $(\mathrm{MPa})$ & 683 & 656 \\
\hline Ultimate tensile Strain $(\%)$ & $1.50 \pm 0.06$ & $1.33 \pm 0.03$ \\
\hline Transverse coefficient of thermal expansion & $27.35 \pm$ & $22.45 \pm$ \\
TCTE $\left(\alpha_{\mathrm{ft}}\right)\left[\mathrm{x} 10^{-6}\right] /{ }^{\circ} \mathrm{C}$ & 0.35 & 0.31 \\
\hline Longitudinal coefficient of thermal expansion & $6.81 \pm 0.9$ & $6.61 \pm$ \\
LCTE $\left(\alpha_{\mathrm{fl}}\right)\left[\mathrm{x} 10^{-6}\right] /{ }^{\circ} \mathrm{C}$ & & 0.1 \\
\hline
\end{tabular}




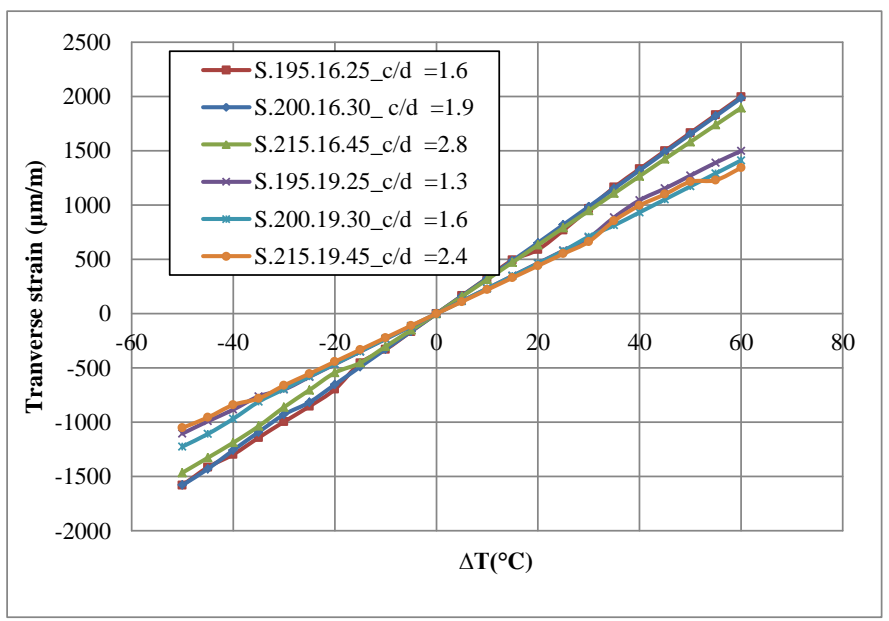

Figure 2. Numerical transverse thermal strains at the FRP bar/concrete interface for reinforced concrete slabs having different ratios of $c / d_{b}$

The difference between the transverse coefficient of thermal expansions of FRP bar and that of concrete induces a radial pressure $\mathrm{P}$ at FRP bar/concrete interface when $\Delta \mathrm{T}$ increases. This radial pressure generates tensile stresses that may cause splitting failure of concrete cover if the confining action of concrete is not sufficient. The transverse tensile thermal strains in FRP bar $\varepsilon_{f t}$ at FRP bar/concrete interface and the transverse tensile thermal strains of concrete $\varepsilon_{c t}$ at the external surface of concrete cover of slabs, due to the radial pressure $\mathrm{P}$ and to the temperature variation $\Delta \mathrm{T}$, are given by the following equations:

$$
\begin{aligned}
& \varepsilon_{\mathrm{ft}}(\mathrm{a})=\alpha_{\mathrm{t}} \Delta \mathrm{T}-\left(1-v_{\mathrm{tt}}\right) \mathrm{P} / \mathrm{E}_{\mathrm{t}} \\
& \varepsilon_{\mathrm{ct}}(\mathrm{b})=\alpha_{\mathrm{c}} \Delta \mathrm{T}+2 \mathrm{P} / \mathrm{E}_{\mathrm{c}}\left(\mathrm{r}_{\mathrm{i}}^{2}-1\right)
\end{aligned}
$$

where $\alpha_{\mathrm{t}}$ and $\alpha_{c}$ are respectively, the transverse coefficients of thermal expansion of FRP bar and concrete; $v_{t t}$ is the Poison's ratio of FRP bar in the transverse direction; $E_{t}$ is the modulus of elasticity of FRP bar in the transverse direction; $\mathrm{E}_{\mathrm{c}}$ is the modulus of elasticity of concrete; $r_{i}=b / a$ is the ratio of concrete cylinder radius to the FRP bar radius.

The radial pressure $(\mathrm{P})$ exerted by the FRP bar on the surrounding concrete interface, obtained from the compatibility equation of the transverse thermal strains, is given by the following equation:

$$
\mathrm{P}=\left(\alpha_{\mathrm{t}}-\alpha_{\mathrm{c}}\right) \Delta \mathrm{T} /\left[\frac{1}{\mathrm{E}_{\mathrm{c}}}\left(\frac{\mathrm{r}_{\mathrm{i}}^{2}+1}{\mathrm{r}_{\mathrm{i}}^{2}-1}+v_{\mathrm{c}}\right)+\frac{1}{\mathrm{E}_{\mathrm{t}}}\left(1-v_{\mathrm{tt}}\right)\right]
$$

where $r_{i}=b / a=\left(2 c+d_{b}\right) / d_{b}(c$ is the concrete cover thickness, and $d_{b}$ is the FRP bar diameter). $v_{c}$ is the Poisson's ratio of concrete.

\section{Iv. Comparison of Theoretical and Experimental Results}

Fig. 4 exhibits typical curve which compare the numerical, experimental and analytical (equation 1) predictions in terms of transverse thermal strains at the FRP/concrete interface ver-

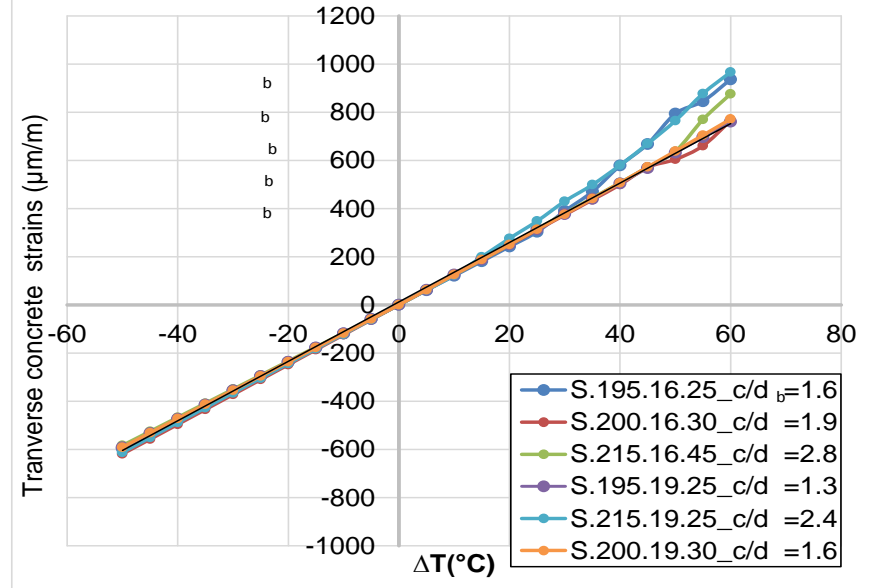

Figure 3. Numerical transverse thermal strains at the external surface of concrete cover for reinforced concrete slabs having different ratios of $\mathrm{c} / \mathrm{d}_{\mathrm{b}}$

sus temperature variation of slab S.195.16.25 having a ratio of concrete cover thickness to FRP diameter $\left(\mathrm{c} / \mathrm{d}_{\mathrm{b}}\right)$ equal 1.6. The experimental results were obtained by Bellakehal et al. (2014). It should be noted that the reference temperature is $+20^{\circ} \mathrm{C}$. Experimentally, the GFRP bars were instrumented by six strain gauges installed in both transverse and longitudinal directions. To measure the transverse and longitudinal strains of concrete, 3 strain gauges were placed on the lower tensioned surface of the slab during thermal tests. All the strain gauges were installed on the mid-span.

The numerical model is in good agreement with the experimental model, but the analytical predictions are widely lower of them. This difference is due to the presence of circumferential cracks in the concrete at low temperature caused by the radial tensile stress generated in concrete at FRP bar/concrete interface. Furthermore, for high temperature, the circumferential thermal tensile stresses caused by the radial pressure exerted by the expansion of FRP bar on concrete generate radial tensile cracks in concrete surrounded FRP bars, as shown in the Fig. 7 (a) and 7 (b). These cracks are not considered in the analytical model based on the elasticity theory.

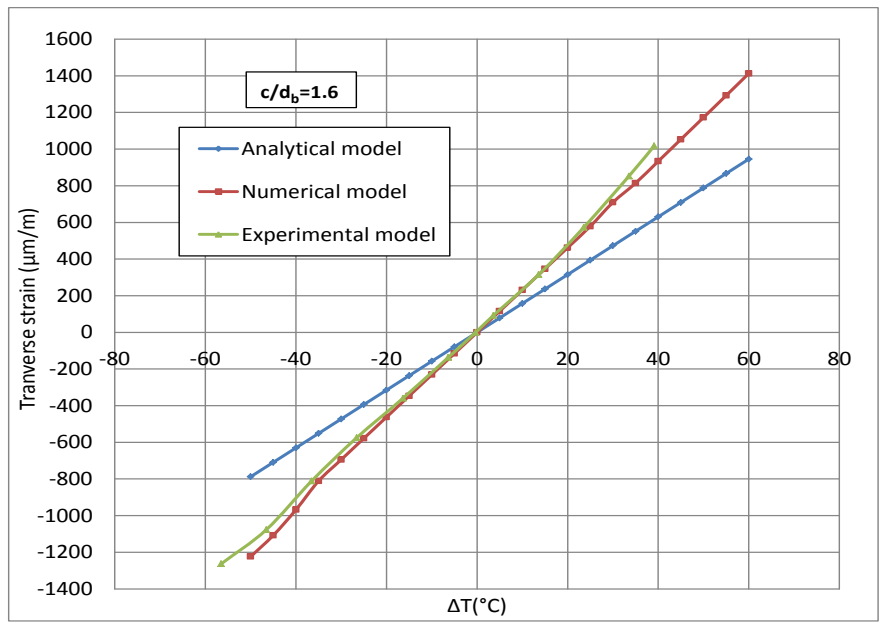

Figure 4. Transverse strains versus temperature variations at FRP bar/concrete interface for slab S.195.16.25 - Comparisons between analytical, numerical and experimental results. 
Proc. of the Sixth Intl. Conf. Advances in Civil, Structural and Mechanical Engineering - CSM 2018

Copyright (C) Institute of Research Engineers and Doctors, USA. All rights reserved.

ISBN: 978-1-63248-150-4 doi: 10.15224/978-1-63248-150-4-24

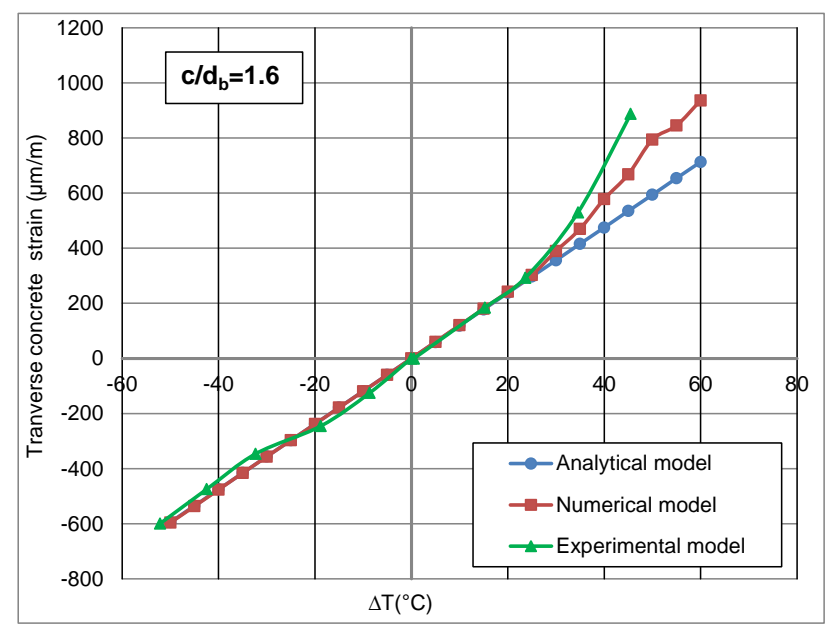

Figure 5. Transverse strains versus temperature variation at the external surface of concrete cover of slab S.195.16.25 - Comparison between analytical, numerical and experimental results.

Fig. 5 and 6 present typical comparisons between numerical, analytical and experimental results in terms of transverse thermal strains versus temperature variations at the external surface of concrete cover of slabs S.195.16.25 and S.215.16.45, respectively. The experimental results were obtained by Bellakehal et al. (2014). For slab S.215.16.45 (Fig. 6), the predicted numerical results are in good agreement with the experimental and analytical results from -50 to $60^{\circ} \mathrm{C}$, because the splitting cracks don't reach the external surface of concrete cover for this slab, as shown in Fig. 7(c).

For slab S.215.16.25 (Fig. 5), the predicted numerical and analytical results are also in good agreement with the experimental results up to temperature variations equal to $30^{\circ} \mathrm{C}$. After that the analytical results are lower than those obtained from numerical and experimental models. This due to the presence of splitting cracks at the outer surface of concrete cover which has not been considered in the analytical model as shown in Fig. 7(d).

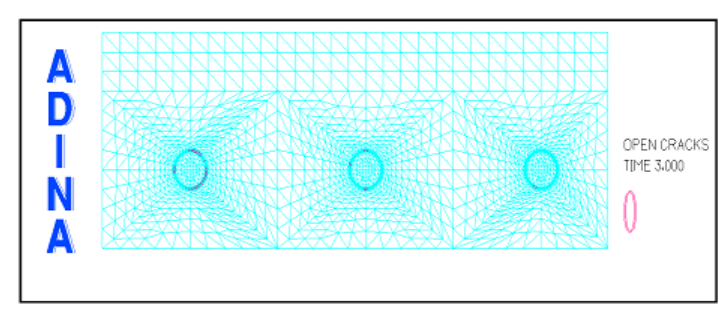

(a) First circumferential cracks in concrete at $\Delta \mathrm{T}=-15^{\circ} \mathrm{C}$ (Slab S.195.16.25 having $\mathrm{c} / \mathrm{d}_{\mathrm{b}}=1.6$ )

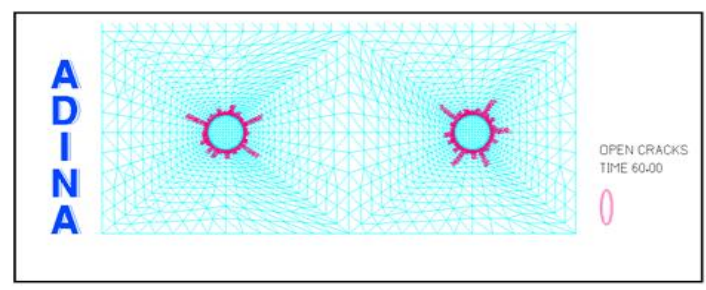

(c) No cracking of concrete cover

(Slab S.215.19.45 having $\mathrm{c} / \mathrm{d}_{\mathrm{b}}=2.4$ )

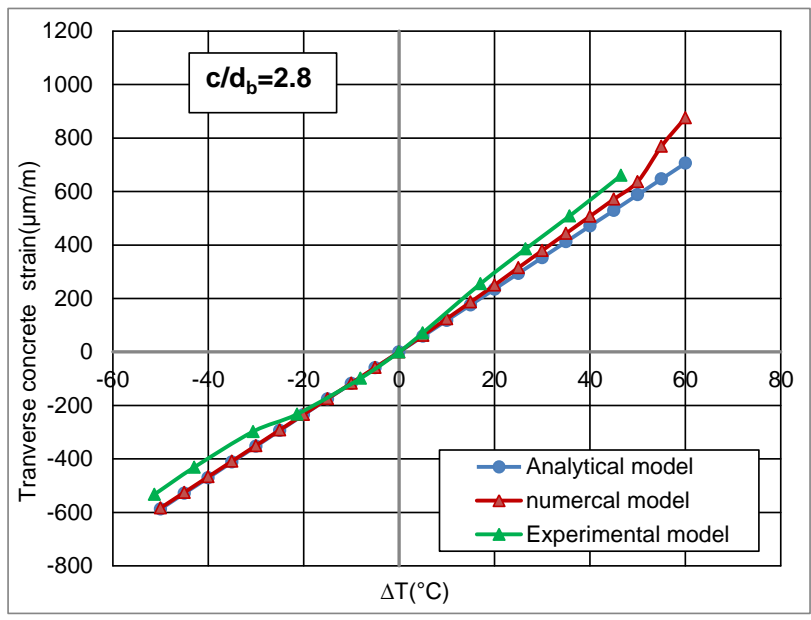

Figure 6. Transverse strains versus temperature variation at the external surface of concrete cover of slab S.215.16.45 - Comparison between analytical, numerical and experimental results.

\section{v. Conclusions}

The theoretical analysis conducted to investigate the thermal behavior of FRP-reinforced concrete slabs having a ratio of concrete cover thickness to FRP bar diameter varied from 1.3 to 2.8 , and submitted to temperature variation varied from -50 to $+60^{\circ} \mathrm{C}$, allow to draw the following conclusions :

- The transverse thermal strains, at FRP bar/concrete interface of concrete slabs reinforced with GFRP bars $\mathrm{N}^{\circ} 16$, are greater than those of concrete slabs reinforced with GFRP bars $\mathrm{N}^{\circ} 19$. This is due to the coefficient of thermal expansion of GFRP bar $\mathrm{N}^{\circ} 16$ which is higher than that of GFRP bar $\mathrm{N}^{\circ} 19$.

- The transverse thermal strains curves, at the external surface of concrete cover, predicted from numerical model, are linear and similar up to the thermal loads producing a total failure of concrete cover.

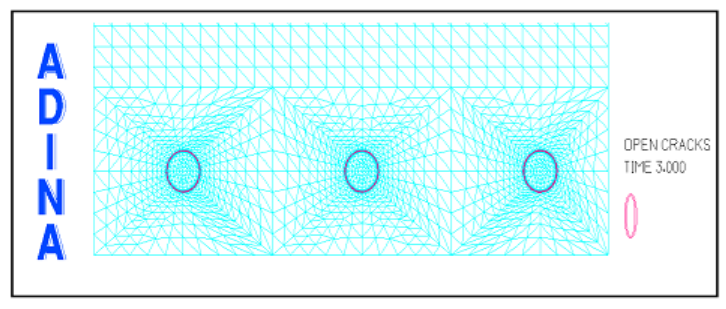

(b) First radial cracks in concrete at $\Delta \mathrm{T}=15^{\circ} \mathrm{C}$ (Slab S.195.16.25 having $\mathrm{c} / \mathrm{d}_{\mathrm{b}}=1.6$ )

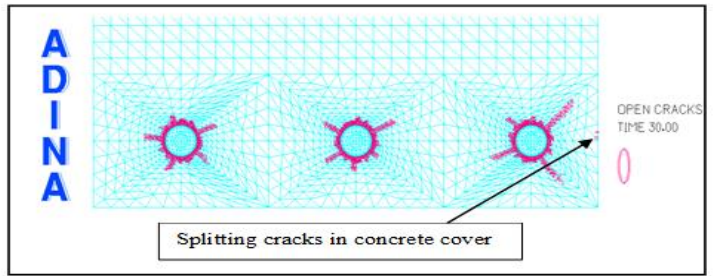

(d) Splitting cracks in concrete cover at $\Delta \mathrm{T}=30^{\circ}$ (Slab S.195.16.25 having $\mathrm{c} / \mathrm{d}_{\mathrm{b}}=1.6$ )

Figure 7. Concrete cracking pattern of slabs S.195.16.25and S.215.19.45. 
- The transverse thermal strain at FRP bar/concrete interface, predicted from the numerical model, are linear up to the thermal loads producing first cracking of concrete.

- The numerical results of transverse thermal strains at FRP bar/concrete interface and at the outer surface of concrete cover are in good agreement with those obtained from experimental tests for temperatures variations varied from -50 to $+60^{\circ} \mathrm{C}$.

- The numerical results of transverse thermal strains at the outer surface of concrete cover are in good agreement with those obtained from the analytical model for temperatures variations less than those producing a total failure of concrete cover.

\section{References}

[1] ADINA R \& D Inc, 1995. Theory and modeling guide. Watertown (MA, USA): ADINA R \& D

[2] M. A. Aiello, F. Focacci, and A. Nanni, "Effects of thermal loads on concrete cover of fiber reinforced polymer reinforced elements: Theoretical and experimental analysis," ACI Materials Journal, Vol. 98(4), pp. $332-339,2001$.

[3] American concrete institute (ACI), "Guide for the design and construction of concrete reinforced with FRP bar, ACI 440. IR-06," Farmington Hills, Michigan, USA, 42PP, 2006.

[4] H. Bellakehal, A. Zaidi, R. Masmoudi, and M. Bouhicha, "Combined effect of sustained load and freeze-thaw cycles on one-way concrete slabs reinforced with glass fibre reinforced polymer," Canadian Journal of Civil Engineering, Vol. 40(11), pp. 1060 - 1067, 2013.

[5] H. Bellakehal, A. Zaidi, R. Masmoudi, and M. Bouhicha, "Behavior of FRP- Reinforced Concrete Slabs under Temperature and Sustained Load Effects," Polymers journal,Vol. 6(3), pp. 873 - 889, 2014.

[6] O. Chaallal, B. "Benmokrane, Physical and mechanical performance of innovative glass fiber reinforced plastic rod for concrete and grouted anchorages," Canadian Journal of Civil Engineering, Vol. 20, pp. 254 268, 1993.

[7] R. Masmoudi, A. Zaidi, P. Gérad, "Tranverse thermal Expansion of FRP bars Embedded in concrete," J. Compos. Constr, ASCE, Vol. 9(5), pp. $377-387,2005$.

[8] H. A. Rahman, C.Y. Kingsley, and D. A. Taylor, "Thermal stress in FRP reinforced concrete," Proceedings Annual Conference of the Canadian Society for Civil Engineering, Ottawa, pp. 605-614, 1995. 